\title{
THE CORRELATION BETWEEN PRESENCE OF EOSINOPHIL WITH HISTOPATHOLOGICAL SUBTYPES IN NASOPHARYNGEAL CARCINOMA $\underline{\text { Nola Puspita Agus }}{ }^{1}$, Delyuzar ${ }^{1}$, Muhammad Nadjib Dahlan Lubis ${ }^{1}$, Soekimin ${ }^{1}$, Joko S Lukito ${ }^{1}$ \\ ${ }^{1}$ Department of Anatomical Pathology, Faculty of Medicine, Universitas Sumatera Utara, Medan, Indonesia
}

\begin{abstract}
Background: Nasopharyngeal carcinoma is a malignancy shows squamous differentiation, incidence rate was $5 \%$ in Indonesia. Eosinophils are granulocytic leukocytes residing in blood and tissues, has been related as a prognostic indicator for cancers. Whether an increase in eosinophils leading to favorable or unfavorable prognosis still remains controversial and depends on many factors including the type of cancer.

Objective: This study was aimed to analyze correlation the presence of eosinophil with histopathologic subtypes in nasopharyngeal carcinoma

Material and Methods: This study was analytic, with cross-sectional approach, which were enrolled 72 slides of NPC biopsy, and assessed by accounting eosinophils in 10 high power field (HPF) with 40X magnification. The result with 0 is nothing eosinophil, $1-4$ is mild infiltration, $5-19$ is moderate infiltration, $\geq 20$ is severe infiltration.

Result: There were more males than females, with the highest age group being 51-60 years and the most common histopathological subtype was non-keratinizing squamous cell carcinoma (NKSCC). In NKSCC subtype, the most common eosinophil infiltration category groups were mild and moderate infiltration as many as $25(39.7 \%)$ samples, and in keratinizing squamous cell carcinoma (KSCC) subtype the most common samples were obtained in mild infiltration category group 5 (55.6\%) samples. Mann Whitney U test was performed on this variable and obtained $\mathrm{p}$-value $0.025(\mathrm{p} \leq 0.05)$.
\end{abstract}

Conclusion: There was correlation between presence of eosinophil with histopathological subtypes in nasopharyngeal carcinoma.

Keywords: nasopharyngeal carcinoma, eosinophil, fa vorable prognosis.

\section{Introduction}

Nasopharyngeal carcinoma (NPC), also known as lymphoepithelioma, was defined as a malignant nasopharyngeal tumor of head and neck. ${ }^{1}$ Histologically, nasopharyngeal carcinoma was divided into three subtypes, which was nonkeratinizing squamous cell carcinoma (NKSCC), keratinizing squamous cell carcinoma (KSCC), and basal squamous cell carcinoma (BSCC). ${ }^{2}$ According to the data from Global Burden of Cancer (GLOBOCAN) 2020, there was approximately 133000 new cases of NPCs, with the 80000 mortality cases. ${ }^{3}$

NPC was on of immunity tumor which was correlated with several inflammatory cells such as lymphocyte and neutrophils which can be used to predict the outcome of the patients with NPC. Chronic inflammation of nasopharynx causes the tissue to be susceptible to carcinogenic substances which may promote nasopharyngeal carcinoma. Inflammation and benign tumor in ears, nose and throat were predisposing factors for the transformation of nasopharyngeal mucosa which will promote malignancy. ${ }^{4,5}$ However, there was no prior study about the correlation between eosinophil and NPC. Based on this background, the author was interested in studying the correlation of the existence of eosinophils on patients with nasopharyngeal carcinoma.

\section{Material and Methods}

This analytical study with retrospective design was conducted in Anatomical Pathology Department in the Medical Faculty of Universitas Sumatera Utara, and Anatomical Pathology unit in the Haji Adam Malik Central General Hospital. This study was conducted from February to June 2021, after obtaining the ethical clearance from Health Research Ethics Committee in the Medical Faculty of Universitas Sumatera Utara. The samples of this study were embedded paraffin 72 tumour tissues, and it were diagnosed as NPC which fulfilled the inclusion and exclusion criteria. Samples were obtained through consecutive sampling method. The criteria of inclusion were that all the paraffin block were sufficient with their 
medical record which consist of age, and sex. The criteria of exclusion for this study were insufficient or damaged paraffin block which cannot be incised again.

Microscope slides was re-examined by the author and two anatomical pathology specialists which was then diagnoses as nasopharyngeal carcinoma, if the diagnose criteria was met. The examination of eosinophil's existence in the microscope slide with nasopharyngeal carcinoma was done by the author and two pathology anatomy specialists which was the author's supervisors. The existence of eosinophils was measured by counting the number of eosinophils under the light microscope with 40x magnification in 10 fields of view which was randomly selected. The number of eosinophils counted was categorized into 4 groups: 1=0 eosinophil: eosinophil was not found, $2=1-4$ eosinophils: mild infiltration of eosinophils, $3=5-19$ eosinophils: moderate infiltration of eosinophils, $4=\geq 20$ eosinophils: severe infiltration of eosinophils.

Data collected in this research were processed by using statistical software, statistical package for the social sciences (SPSS22) version, and presented in tables. Statistical tests used in this study were Chi-square and Mann Whitney U test.

\section{Results}

In this study, 72 samples which fulfilled the criteria of inclusion was examined and the numbers of eosinophils was counted. The distribution of the characteristic of the samples in this study can be seen in the table below (Table 1).

Table 1. Distribution of the characteristic of samples

\begin{tabular}{|c|c|c|}
\hline Characteristic & Total $(n=72)$ & Percentage $(\%)$ \\
\hline \multicolumn{3}{|l|}{ Sex; } \\
\hline - $\quad$ Male & 48 & 66.7 \\
\hline - Female & 24 & 33.3 \\
\hline \multicolumn{3}{|l|}{ Age (years); } \\
\hline - $<20$ & 3 & 4.2 \\
\hline - $\quad 21-30$ & 2 & 2.8 \\
\hline - $\quad 31-40$ & 8 & 11.1 \\
\hline - $\quad 41-50$ & 20 & 27.8 \\
\hline - $\quad 51-60$ & 28 & 38.9 \\
\hline - $\quad>60$ & 11 & 15.3 \\
\hline \multicolumn{3}{|l|}{ Histopathological subtype; } \\
\hline - NKSCC & 63 & 87.5 \\
\hline - $\mathrm{KSCC}$ & 9 & 12.5 \\
\hline \multicolumn{3}{|l|}{ Presence of eosinophils; } \\
\hline - $\quad$ Not found & 11 & 15.3 \\
\hline - $\quad$ Mild infiltration & 31 & 43.1 \\
\hline - Moderate infiltration & 24 & 33.3 \\
\hline - $\quad$ Severe infiltration & 6 & 8.3 \\
\hline
\end{tabular}

From Table 1. we can see that in this study, 48 samples were male and 24 samples were female, with the majority of the samples was from 51-60 years old group of age (28 samples). Most histopathology subtype found was NKSCC. The highest numbers of eosinophil count are in the mild infiltration of eosinophils category, which was 31 (43.1\%) samples and the lowest numbers of eosinophil count was in the severe infiltration of eosinophils group, which was 6 (8.3\%) samples. 
Table 2. Characteristic sex and age in histopathological subtype

\begin{tabular}{|c|c|c|c|c|c|c|}
\hline \multirow{3}{*}{ No. } & \multirow{3}{*}{ Characteristic } & \multicolumn{4}{|c|}{ Histopathological Subtype } & \multirow{3}{*}{ p-value } \\
\hline & & \multirow[b]{2}{*}{$\mathbf{N}$} & NKSCC & \multicolumn{2}{|c|}{$\mathrm{KSCC}$} & \\
\hline & & & $\%$ & $\mathbf{N}$ & $\%$ & \\
\hline \multirow[t]{3}{*}{1.} & Sex; & & & & & \\
\hline & Male & 42 & 87.5 & 6 & 12.5 & $1.000 *$ \\
\hline & Female & 21 & 87.5 & 3 & 12.5 & \\
\hline \multirow[t]{7}{*}{2.} & Age (years old); & & & & & \\
\hline & $\leq 20$ & 3 & 100 & 0 & 0 & \\
\hline & $21-30$ & 2 & 100 & 0 & 0 & \\
\hline & $31-40$ & 8 & 100 & 0 & 0 & $0.051 * *$ \\
\hline & $41-50$ & 18 & 90 & 2 & 10 & \\
\hline & $51-60$ & 24 & 85.7 & 4 & 14.3 & \\
\hline & $\geq 60$ & 8 & 73.7 & 3 & 27.3 & \\
\hline
\end{tabular}

From Table 2. we found that in the NKSCC subtype, 42 samples were male and 21 samples were female. In the KSCC subtype, 6 samples were male and 3 samples were female. The Chi-Square showed the result of $p$-value $=1.000(p>0.05)$. In the NKSCC and KSCC subtypes, most of the samples were from the 51-60 years old group of age. The Mann-Whitney $\mathrm{U}$ test showed the result of $\mathrm{p}$-value $=0.051(\mathrm{p}>0.05)$.

Table 3. Correlation between the presence of eosinophils with histopathological subtypes

\begin{tabular}{|c|c|c|c|c|c|c|}
\hline \multirow{3}{*}{ No. } & \multirow{3}{*}{ Eosinophil Infiltration } & \multicolumn{5}{|c|}{ Histopathological Subtype } \\
\hline & & \multicolumn{2}{|c|}{ NKSCC } & \multicolumn{2}{|c|}{ KSCC } & \multirow[t]{2}{*}{ p-value* } \\
\hline & & $\mathbf{N}$ & $\%$ & $\mathbf{N}$ & $\%$ & \\
\hline 1. & Negative & 8 & 12.7 & 3 & 33.3 & \\
\hline 2. & Mild & 25 & 39.7 & 5 & 55.6 & 0.025 \\
\hline 3. & Moderate & 25 & 39.7 & 1 & 11.1 & \\
\hline \multirow[t]{2}{*}{4.} & Severe & 5 & 7.9 & 0 & 0 & \\
\hline & Total & 63 & 100 & 9 & 100 & \\
\hline
\end{tabular}

From Table 3. we found that there was correlation between the existence of eosinophils with histopathology subtype in nasopharyngeal carcinoma. In which in the NKSCC subtype group, the highest number for the eosinophil infiltration category was mild to moderate infiltration which was $25(39 / 7 \%)$ of the samples and in the KSCC subtype the highest number for the eosinophil infiltration category was mild infiltration which was $5(55.6 \%)$ samples. The Mann-Whitney U test showed the result of $\mathrm{p}$-value $=0.025(\mathrm{p}<0.05)$. 


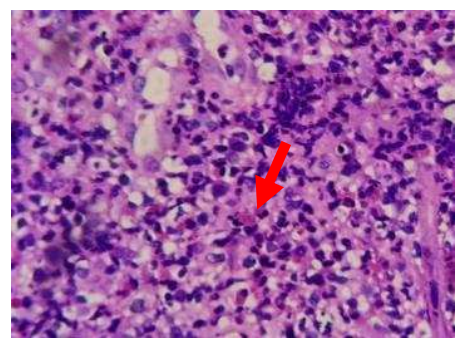

Figure 1. Overview of eosinophils in nasopharyngeal carcinoma from research samples (red arrow)

\section{Discussion}

NPC was a malignancy from the epithelial tissue of nasopharynx, it was a malignant tumour of head and neck. ${ }^{2}$ NPC has an outstanding ethnic and geographical distribution, with a very high prevalence in South China, South-East Asia and North Africa. Based on the data from GLOBOCAN 2020, there was approximately 133000 new cases of NPC..$^{5}$ Nuraini et al. found 60 cases of NPC in Haji Adam Malik General Hospital in 2018. NPC was more common in male than female. ${ }^{6}$

In this study, there were 72 samples of nasopharyngeal carcinoma with NKSCC and KSCC subtypes which fulfilled the criteria of inclusion and exclusion. Most of the samples were male, which was 48 samples (66.7\%). The rate of male to female comparison was $2: 1$. This was in line with prior study by Adham et al. which found that there were more male NPC patients compared to female. ${ }^{7}$ This was probably influenced by the difference of lifestyle (tobacco consumption). Also, this was probably correlated with the type of works that male tend to do which make them more susceptible to carcinogenic substances such as dust, formaldehyde, heat, smoke, and other chemical substance which was a risk factors for nasopharyngeal carcinoma. ${ }^{2}$ The sex characteristic analysed was compared with the NKSCC and KSCC subtype, the Chi-Square test showed the result of $p$-value $=1.000(\mathrm{p}>0.05)$, which means that there was no correlation between sex and nasopharyngeal carcinoma with NKSCC and KSCC subtypes. This was in line with prior study by Munir which stated that there was no significant correlation between sex and the histologic subtype of nasopharyngeal carcinoma. ${ }^{8}$

This study showed that the distribution of nasopharyngeal carcinoma was mostly in the 51-60 years old group of age. The youngest sample was 14 years old and the oldest sample was 73 years old. Wu et al. found that NPC may affect all group of age. ${ }^{9}$ Faiza et al. also found that NPC may affect all group of age, with the highest incidents in the 40-60 years old group of age. ${ }^{10}$ High prevalence in older people might be affected by the deceasing immune system, which makes it harder for the body to eliminate Epstein-Barr Virus (EBV) or the tumour antigen. ${ }^{2}$ Also, statistical analysis used to evaluate the characteristic of age was correlated to the NKSCC and KSCC subtypes, the Mann-Whitney U test showed the result of $p$-value $=0.051(\mathrm{p}>0.05)$, this means that there was no correlation between age and nasopharyngeal carcinoma with NKSCC and KSCC subtypes. The study of Qu et al. showed a similar result that there was no significant correlation between age and the histologic subtype of NPC. ${ }^{11}$

This study also examined the distribution of nasopharyngeal carcinoma based on its subtype. The highest number was in NKSCC subtype which was $63(87.5 \%)$ samples. Shah et al. found that the most common subtype of nasopharyngeal cancer was Undifferentiated NKSCC (60-65\%), Differentiated NKSCC (10-15\%). ${ }^{1}$ Faiza et al. also found that the most common histopathologic type was differentiated NKSCC which was 75\%, followed by differentiated NKSCC which was $11.36 \% .^{10}$ This result was similar with the literature that stated that the most common histopathologic subtype found was NKSCC, especially undifferentiated NKSCC. NKSCC was the most prevalent in South-East Asia and several other regions with high incidence of NPC, and it was correlated strongly with EBV infection. ${ }^{7}$

One of the goals of this study is to analyse the correlation of the existence of eosinophils with the histopathologic subtype of NPC. In which in NKSCC subtype the highest number for the eosinophil infiltration category was mild and moderate infiltration which was $25(39.7 \%)$ samples and in the KSCC subtype it was found that the highest number for the eosinophil infiltration category was mild infiltration which was $5(55.6 \%)$ samples. The categorization of the existence of eosinophils was also used by prior studies. Khatibi et al. studied the quantification of eosinophils in oral squamous cell carcinoma (OSCC). They examined the number of eosinophils in $10 \mathrm{HPF}$ such as follows; no infiltration (0): one case (1.2\%), poor infiltration: 3 cases $(3.6 \%)$, moderate infiltration: 14 cases $(16.9 \%)$, severe infiltration: 49 cases $(59 \%) .{ }^{12}$ Another study also categorized the existence of eosinophils such as the study conducted by Fadhilaturrahmi et al. this study aims to understand the correlation of eosinophils with the eosinophilic amorphic structure in the patients with tuberculous lymphadenitis. There was an absence of eosinophil, poor infiltration, moderate infiltration and severe infiltration. ${ }^{13}$ The Mann-Whitney $U$ test showed the result of $p$-values $=0.025(\mathrm{p}<0.05)$. This means that there was a correlation between the existence of eosinophils with the histopathologic subtype of NPC. This was in line with prior study by Khatibi et al, which uses Kruskal-Wallis test which showed that there was a significant correlation between the 
quantitative value of eosinophils in $\operatorname{OSCC}(\mathrm{p}=0.04)$, which means that the decrease of tumour associated tissue eosinophilia (TATE) with higher level of histologic level and worsened tumour differentiation, which emphasize the antitumour role of eosinophils. ${ }^{12}$ The study by Deepthi et al. also showed a higher number of eosinophils in OSCC subtype compared to dysplasia, which means that the number of eosinophils can be used as an additional factor to predict the malignant transformation of the lesion in OSCC. ${ }^{14}$ Another author such as Peurala et al. tried to simplify TATE evaluation and found the limitation of patients with four eosinophils per each large field of view with the patients that had more than four eosinophils per HPF showed a better quality of life. However, another publication showed that the infiltration of eosinophilic tumour is a marker of poor prognosis in patients with OSCC. ${ }^{15}$

From the result of this study, the author concluded that the existence of eosinophil in tumour might be a predictor of good outcome. In several neoplasm (such as melanoma, gastric, colorectal, and prostate tumour) eosinophils plays an antitumour effects, in another neoplasm (such as Hodgkin lymphoma) it was correlated with poor outcome. This different in result showed that the role of eosinophils might be different, according to type of cancer. ${ }^{16,17}$ However, the controversies of the prognostic value reported might also be influenced by several other factors, and this was not yet known. ${ }^{17}$

The limitation of this study is the difficulties in examining the peritumoral eosinophil due to the difficulties in recognizing the tumour border with the minimal biopsy sample. Due to this, the future study could use more represented biopsy.

\section{Conclusion}

This study concluded that there was correlation between the existence of eosinophils with the histopathologic subtype in nasopharyngeal carcinoma.

\section{Competing Interests}

The author has had no financial interest with the products or companies mentioned in the article.

\section{Acknowledgment}

We would like to thank all staffs of the Department of Anatomical Pathology, Universitas Sumatra Utara, and Haji Adam Malik General Hospital.

\section{Ethical Approval}

Health Research Ethical Committee, Universitas Sumatera Utara, Medan, Indonesia approved this study.

\section{References}

1. Shah AB, Zulfiqar H, Nagalli S. Nasopharyngeal carcinoma. National Institutes of Health. 2020.

2. Petersson BF, Beli D, Lewis JS, Nadal A, Nicolai P, Wenig BM, et al. Nasopharyngeal carcinoma. In: El-Naggar AK, Chan JKC, Grandis JR, Takata T, Slootweg PJ, editors. WHO classification of head and neck tumours $4^{\text {th }}$ ed. Lyon: IARC. 2017; pp.65-70.

3. Sung H, Ferlay J, Siegel RL, Laversanne M, Soerjomataram I, Bray F, et al. Global cancer statistic 2020: GLOBOCAN estimates of incidence and mortality worldwide for 36 cancers in 185 countries. American Cancer Society Journal. 2021.

4. Deepthi G, Kulkarni PG, Nandan SR K. Eosinophils: An imperative histopathological prognostic indicator for oral squamous cell carcinoma. Government College and Hospitals. 2019.

5. Zeng X, Liu G, Pan Y, Li Y. Development and validation of immune inflammation-based index for predicting the clinical outcome in patients withnasopharyngeal carcinoma. Journal of Cellular and Molecular Medicine. 2020.

6. Nuraini E, Betty, Lubis MND. Expression of programmed death-ligand 1 (PD-L1) immunohistochemistry staining in nasopharyngeal carcinoma at Rumah Sakit Umum Pusat Haji Adam Malik Medan 2018. International Journal of Research Publication. 2020. Vol.54

7. Adham M, Kurniawan AN, Muhtadi AI, Roezin A, Herman B, Gondhowiardjo S, et al. Nasopharyngeal carcinoma in indonesia: Epidemiology, incidence, signs, and symptoms at presentation. Chinese Journal of Cancer. 2012; 31:185-196.

8. Munir D. Beberapa aspek karsinoma nasofaring pada suku batak di Medan dan sekitarnya. Majalah Kedokteran Nusantara. 2006; 39.

9. Wu L, Li C, and Pan L. Nasopharyngeal carcinoma: a review of current updates. Experimental And Therapeutic Medicine. 2018; 15: 3687-3692.

10. Faiza S, Rahman S, Asri A. Karakteristik Klinis dan Patologis Karsinoma Nasofaring di Bagian THT-KL RSUP Dr.M.Djamil Padang. Jurnal Kesehatan Andalas. 2016; 5(1).

11. Qu Y, Wang D, Yang L, Liu H, Cui W, Che Y. Expression and clinical significance of programmed death ligand 1 in nasopharyngeal carcinoma. Molecular and Clinical Oncology. 2018; 9: pp.75-81.

12. Khatibi AH, Sabzijate M, Ghiasian T, Rahrotaban S, Rastegar E, Eftekharian SH. Quantification analysis of tissue eosinophilia in squamous cell carcinoma of the head and neck region. Bali Medical Journal. 2018; 7(1): pp.165-169. 
13. Fadhilaturrahmi, Delyuzar, Lubis MND. The Correlation between eosinophil and eosinophilic amorphous structure in tuberculous lymphadenitis patients. International Journal of Scientific and Research Publications. 2021; 11(1).

14. Deepthi G, Kulkarni PG, Nandan SR K. Eosinophils: An imperative histopathological prognostic indicator for oral squamous cell carcinoma. Government College and Hospitals. 2019.

15. Peurala E, Tuominen M, Loyttyniemi E, Syrjanen S, Rautava J. Eosinophilia is a favorable prognostic marker for oral cavity and lip squamous cell carcinoma. APMIS: acta pathologica, microbiologica, et immunologica Scandinavica. 2018; 126(3): 201-207.

16. Varricchi G, Galdiero MR, Loffredo S, Lucarini V, Marone G, Mattei F, et al. Eosinophils: The unsung heroes in cancer? Department of Translational Medical OncoImmunology. 2017.

17. Simon SCS, Utikal J, Umansky V. Opposing roles of eosinophils in cancer. Cancer Immunology, Immunotherapy. 2019; 68: 823-833. 